American Journal of Applied Sciences 7 (10): 1379-1386, 2010

ISSN 1546-9239

(C) 2010 Science Publications

\title{
Competencies Influencing Extension Workers' Job Performance in Relation to the Good Agricultural Practices in Malaysia
}

\author{
Neda Tiraieyari, Khairuddin Idris, Jegak Uli and Azimi Hamzah \\ Department for Social Science Studies (IPSAS), University Putra Malaysia, Malaysia
}

\begin{abstract}
Problem statement: The bottom line in agricultural trade is that manufacturers are demanding agricultural products that are produced in a sustainable way and with assurance that they are truly conforming to the standards of Good Agriculture Practice. Towards this objective, attention has been given on sustainable agricultural productions in Malaysia. This study is an attempt to investigate job performance of extension workers in terms of competency in relation to the Good Agricultural Practices. This research investigates the influence of competencies on extension workers' job performance at the department of agriculture in Malaysia with the emphasis of having both human development competencies and technical competencies in order to perform extension job. Approach: Stratified random sampling technique employed to select 210 extension workers from the Department of Agriculture in four states of Malaysia. A structured research instrument was utilized to survey extension workers' competency and job performance. To test the extent research data support the MLR model, Enter regression method was used. Results: Results showed that out of the nine competencies included in the regression model only four competencies contributed significantly in explaining the variation of job performance. The $\mathrm{R}^{2}$ value of 0.544 implies that the nine predictors explain about $54.4 \%$ of the variance in the extension workers' job performance. Conclusion/Recommendations: The findings suggest that the data dose not fully support the proposed nine-predictors multiple linear regression model. Finding was contrary to the expectations, since human development areas of competencies did not contribute to the job performance. Hence extension workers are not much involved in human development aspects of their job and they give primary attention to technology transfer rather than human development.
\end{abstract}

Key words: Competency, job performance, good agricultural practices, extension workers

\section{INTRODUCTION}

Transfer of technology and development of clients' capacity and potential has been identified as two key factors in ensuring effectiveness of any extension service (Bennett, 1989; Benet, 1993). The transfer of technology aims to communicate effectively the result of research to clients and development of clients' capacity and potential through educational activities aims to nurture a self motivated clients who can act voluntarily in their society and able to make rational decisions and solve their problems. The effectiveness of extension services is also highly dependent on the ability of extension workers who are competent as the whole extension process is dependent on them to transfer information from extension organizations to the clients. Previous studies have identified various competencies needed by extension workers in technical areas and human development areas as well. It was found that these competencies should be possessed by extension workers in order to effectively perform their role (Gibson and Hillison, 1994; Cooper and Graham, 2001; Miller and Cox, 2006). However these studies have not linked competencies to extension workers' job performance. Moreover few studies have appeared that examined the influence of human development competencies and technical competencies to extension workers' job performance (Khalil et al., 2008; Thach et al., 2008). Hence this study is an attempt to investigate job performance of extension workers in terms of competency on both human development areas and technical areas in relation to the Good Agricultural Practice. To fill this gap this research investigates the influence of competencies on extension workers' job performance at the Department of Agriculture in Malaysia with the emphasis of having both human development competencies and technical competencies in order to perform extension job.

This study aimed to study with extension workers who have been dealing with farmers implementing

Corresponding Author: Neda Tiraieyari, Department for Social Science Studies (IPSAS), University Putra Malaysia, Malaysia 
Am. J. Applied Sci., 7 (10): 1379-1386, 2010

GAP. The department of agriculture has earmarked Malaysian farm certification scheme for Good Agricultural Practice as a new technology that should be transferred by extension workers to the farmers. The main purpose of this study is to find out competencies that help to explain extension workers' job performances. In relation to this, the present study addresses to provide answer to what competencies influencing extension workers' job performances?

Agriculture in Malaysia: Agriculture has played an important role in the development of Malaysia's economy, contributing $9 \%$ of GDP, $4 \%$ of export tax, $6 \%$ of export earning and employed $13 \%$ of total labor. The government's policy towards agriculture focuses on increasing production, in order to achieve food selfsufficiency and to develop exports. However $90 \%$ of farmers in the food sector are smallholders with uneconomic-sized farms, the cost of production of these smallholders is high, with low input, low yield and poor quality produce. The bottom line in agricultural trade is that manufacturers are demanding agricultural products that are produced in a safe and sustainable way and with assurance that they are truly conforming to standards of Good Agriculture Practice (GAP). Towards this objective, attention has been given on sustainable agricultural productions. At present, GAP is not accepted and properly practiced by majority of farmers in the Malaysian smallholders sector (Othman, 2006). For that purpose the mission of the Department of Agriculture (DOA) currently includes provision of extension services to the farmers in relation to GAP. However the effectiveness of extension education is dependent on the ability of extension workers who must be competent and qualified as the whole extension process is dependent on them to transfer new practices to farmers. Extension workers must be able to perform their roles toward outstanding performance.

The first GAP scheme for food crops introduced in Malaysia was the Malaysian Farm Certification Scheme for Good Agricultural Practice (Skim Amalan Ladang Baik Malaysia) with acronym SALM. The scheme was developed by the Department of Agriculture of the Ministry of Agriculture and Agro-based Industry, modeled after Eurepgap and later was modified to suit the needs of the local and international markets. It was launched in the year 2002 (Othman, 2006).

Competency performance relationships: The link between competency and performance is well established. Competency correlated with performance. It means competent extension workers, perform higher. Dhanakumars (2001) and Linders (2001) reported that job performance and extension competencies are positively related. Similarly Armstrong (2003) stated that competencies are factors that contribute to high levels of individual and organizational performance. On the other hand, by developing a set of competencies for extension workers and incorporating those competencies into training, the capacity of an extension organization to better serve its clients can be improved (Liles and Mustian, 2004). This definitely can increase the rate of adoption of new technologies by clients.

Study conducted by Khalil et al. (2008) to determine the relationships between competencies, organizational commitment and job satisfaction with job performance of extension workers in Yemen. The results of their study revealed a positive relationship between leadership development competency and extension workers' job performance $(r=0.50 ; p=0.001)$. They further reported program evaluation competency predicts extension workers' job performance. Some research found interpersonal skills to be the best single predictor of job performance ratings (Wayne et al., 1997). Similarly Ferris et al. (2001) reported that social skills as the single strongest predictor of performance rating dimensions of task performance, job dedication and interpersonal facilitation, as well as for an overall rating of performance.

Results of investigation conducted by Payne (2005) indicated that high performing employees were more skilled at communicating empathy, adapting their communication and managing interactions with others than lower performing employees. Similarly findings of another research showed that possession of social competence led to a good prediction of job performance (Riggo and Tylor, 2000). Findings of a research indicated that among all individual factors, social skill is strongest contribution in explaining the extension workers' performance (Thach et al., 2008). The result of regression analysis in the study of analysis of the job performance of the agricultural extension experts of Iran conducted by Rezaie et al. (2008) revealed that job ability (competency) contribute $48.6 \%$ of the variance in job performance of extension workers.

Extension workers must be competent in technical area of their job in terms of knowledge and skills in new technology. Results of study conducted by Tiraieyari et al. (2009) showed job performance of extension workers is positively related to technical aspect of their job related to the Good Agricultural Practices $(r=0.356, p=0.001)$. Boyd (2003) stated that successful extension workers should have strong technical knowledge and skill (competency). Similarly Belay and Abebaw (2004) contended that higher rates of technology adoption by clients are achieved when 
extension workers possess adequate technical competency.

Cultural competency has also become a necessity for service providers, professionals and agencies (Olsen et al., 2006). Since extension is a non-formal educational function that applies to any institution/agency that disseminates information with the intention of upgrading knowledge, attitudes, skills and aspirations of the people (Rivera and Qamar, 2003), cultural competency indeed appear to be necessity for extension agency and extension worker as well. Results of study carried out by Tiraieyari (2009) showed that Performance of extension workers is positively related to Cultural competency $(\mathrm{r}=0.611, \mathrm{p}=0.001)$. With the help of this competency extension worker will be able to serve all rural people and bridge across culturally differences and ultimately improve the extension outcomes and performances.

Extension models: There are several extension models in the literature. However Bennett (1989) describes three generic models of extension: Research transfer model or Transfer of Technology (TOT), adult education model (HRD) or farm first and interdependence model of extension.

Research transfer model or Transfer of Technology (TOT): According to this model extension workers' role would be transfer of technology from research agencies to the farmers. Major criticism of this view lies in the fact that too much emphasis is given on the transfer of technology with little or no concern at all to the recipients of technology.

Adult education model (HRD) or farm first: Focuses of this model is on the educational activities to develop farmers' potentials and capabilities. Extension workers empower individual farmers to make rational decision (Benet, 1993).

Interdependence model: This model encompassing the (TOT) and (HRD) and it has been identified as key factors in ensuring effectiveness of extension services. Interdependence model of extension combine the perspective of extension held by HRD and TOT models (Bennett, 1989). The TOT means to communicate effectively the result of research to the farmers. HRD focuses on the educational activities to nurture a self motivated client who can act voluntarily and rationally based on his/her own decision and who has a sense of self-responsibility and social responsibility. The goal of extension is unleashing the potential of clients and developing their capabilities to their full potential. To ensure effectiveness of extension work, the TOT and HRD should be together in implementation of extension services and activities by extension workers. According to this model, extension disseminates information about the adoption of specific practices to the farmers. Furthermore extension goes beyond the role of transferring information about the adoption of specific practices. Extension helps farmers make decisions by enabling them to employ effective processes in decision making and problem solving. Extension's role is strengthening farmers' decision-making processes (Bennett, 1989). The model suggests that extension has a comparative advantage in performing the role of education farmers rather than the role of transfer of technology itself. Furthermore this model helps to understand the transfer of technology and to develop clients' capacity and potential as two main roles of extension workers. Therefore extension workers need certain competencies in technical area and human development area in order to perform their responsibilities and activities well. Its important to note that this study is based on the interdependence model of extension that encompassing transfer of technology and development farmers' capacity and potential as key factors in ensuring effectiveness of extension services and extension workers' roles.

Objectives of the study: Assess the proposed ninefactor regression model to explain the variation of extension workers' job performance.

\section{MATERIALS AND METHODS}

Variables of study: Job performance has been conceptualized as performance of specific dimensions. In this study, extension workers' job performance, dependent variable was measured using different functions of their job. Respondents were asked to assess their performance on eleven dimensions of job performance: Quantity of study, quality of study, timeliness, effectiveness of study, knowledge and skill in study, implementation of Policy/Procedures and direction, effectiveness of communication, ability to manage, discipline, pro-active and innovative and relationship and co-operation. The instrument contained eleven dimensions of job performance and in total 46 items that extension workers are supposed to perform in their current position.

There are nine independent variables in this study:

- The Leadership development competency was measured by 11 items indicating the extent of extension workers' ability to provide clients with 
leadership development training program in terms of developing and enhancing various intra-personal qualities and interpersonal skills

- Problem solving/decision making development competency was measured by the extent of extension workers' ability to provide clients with problem solving/decision making development training program. The process of identifying problems, securing relevant information, developing alternative courses of action and the readiness of making a decision from the information gathered. Six items were developed for this variable

- Competency on SALM certificate measured by the extent of extension workers' knowledge on the roles of Malaysian Farm Certification Scheme for Good Agricultural Practice (SALM). Due to the several of rules and conditions of SALM program which need to learn and practice by farmers, this study chose to focus on critical aspects of SALM. Hence 13 items were selected randomly from a list of critical aspects of SALM to measure technical skills of extension workers on the roles of SALM standard program according to Malaysian Farm Certification Scheme for Good Agricultural Practice (SALM)

- The social competency consists of 27 items measuring extension workers' ability to interact effectively with farmers, colleagues and supervisor and to adjust their behavior to different situational demands

- Cultural competency comprises six items quantifying the extent of extension workers' ability to understand and work within cultures of farmers in process of technology transfer

- Program planning competency was measured by the extent of extension workers' ability to plan extension program such as ability to gather data, analysis of situation, problem identification and setting objectives. Five items were developed by researcher to measure this competency

- Program implementation competency was measured by the extent of extension workers' ability to implement activities which are geared towards solving the identified problems. Four items were developed to measure this variable

- Program evaluation competency was measured by the extent of extension workers' ability to determine value or amount of success in achieving predetermined objectives of technology transfer. Eleven items were developed to measure this competency

- Extension teaching methods competency measured by the extent of extension workers' ability to use variety of extension teaching methods such as conduct extension meetings, conduct method demonstration, field visit tours and results demonstration. Ten items were developed to measure this competency

Quantitative data were collected through a researchers-developed questionnaire. The questionnaire contained Likert-type questions were derived from previous literature. The study employed a geographical stratified sampling method. West Malaysia is divided into four regions. First one state was randomly selected from each region. Then samples were chosen with technique called proportional sample allocation. From each state, respondents were picked at random from the complete list of respondents. A drop-off and pick-up method was adopted to collect data from the respondents. Research data were entered and analyzed using the Statistical Package for the Social Sciences version 15.0 (SPSS 15.0).

According to G-power method, for the F-test in Multiple Regression, by specifying the values of effect size, $\mathrm{f}^{2}=0.15$ (Medium), $\alpha=0.05$, power $=0.95$ and number of predictors $=9$, the minimum suggested sample size using $\mathrm{G}^{*}$ power is 166 , however the larger the size the lesser the sampling error. Hence the required total sample size for the study was specified as 210. This is a sufficient sample for a good representative of the population of approximately 651 .

Table 1: Reliability statistics (Cronbach's alpha) for each variable

\begin{tabular}{llll}
\hline & Number of items & Cronbach's $\alpha$ pilot study $(\mathrm{n}=20)$ & Cronbach's $\alpha$ actual study $(\mathrm{n}=210)$ \\
\hline Leadership development competency $\left(\mathrm{X}_{1}\right)$ & 11 & 0.929 & 0.888 \\
Decision making/Problem solving development & 6 & 0.851 & 0.917 \\
Competency $\left(\mathrm{X}_{2}\right)$ & & & 0.787 \\
SALM program competency $\left(\mathrm{X}_{3}\right)$ & 13 & 0.915 & 0.873 \\
Social competency $\left(\mathrm{X}_{4}\right)$ & 15 & 0.941 & 0.920 \\
Cultural competency $\left(\mathrm{X}_{5}\right)$ & 6 & 0.744 & 0.915 \\
Program planning competency $\left(\mathrm{X}_{6}\right)$ & 5 & 0.874 & 0.896 \\
Program implementation competency $\left(\mathrm{X}_{7}\right)$ & 4 & 0.930 & 0.919 \\
Program evaluation competency $\left(\mathrm{X}_{8}\right)$ & 11 & 0.928 & 0.938 \\
Extension teaching methods competency $\left(\mathrm{X}_{9}\right)$ & 10 & 0.960 & 0.942 \\
Job performance $(Y)$ & 46 & 0.973 \\
\hline
\end{tabular}


Validity and reliability of the instrument: The items were reviewed by various faculty members from University Putra Malaysia. The instrument was pilot tested with 20 extension workers from the Selangor state of Malaysia. Reliability analysis was also performed for each scale. The results of reliability statistics for overall job performance were 0.960 . The Cronbach's coefficient alpha for 9 competencies ranged from 0.787-0.941(Table 1).

\section{RESULTS}

The objective of this study was to identify the best predictors for extension workers' job performance. To gain a better understanding of competencies that influence or help to explain extension workers' job performances, a-nine predictors Multiple Linear Regression (MLR) model was proposed to explain the variation of job performance among extension workers.

The nine predictors of the MLR model of job performance were competency on leadership development $\left(\mathrm{X}_{1}\right)$, competency on problem solving/decision making development $\left(\mathrm{X}_{2}\right)$, competency on SALM certificate program $\left(\mathrm{X}_{3}\right)$ and social competency $\left(\mathrm{X}_{4}\right)$, competency on culture of clients $\left(\mathrm{X}_{5}\right)$, Competency on program planning $\left(\mathrm{X}_{6}\right)$, competency on program implementation $\left(\mathrm{X}_{7}\right)$, competency on program evaluation $\left(\mathrm{X}_{8}\right)$ and competency extension teaching methods $\left(\mathrm{X}_{9}\right)$.

The Eq. 1 proposed multiple linear regression models is as follows:

$$
\begin{aligned}
\mathrm{Y}= & \mathrm{b}_{0}+\mathrm{b}_{1}\left(\mathrm{X}_{1}\right)+\mathrm{b}_{2}\left(\mathrm{X}_{2}\right)+\mathrm{b}_{3}\left(\mathrm{X}_{3}\right)+\mathrm{b}_{4}\left(\mathrm{X}_{4}\right)+\mathrm{b}_{5}\left(\mathrm{X}_{5}\right) \\
& +\mathrm{b}_{6}\left(\mathrm{X}_{6}\right)+\mathrm{b}_{7}\left(\mathrm{X}_{7}\right)+\mathrm{b}_{8}\left(\mathrm{X}_{8}\right)+\mathrm{b}_{9}\left(\mathrm{X}_{9}\right)+\mathrm{e}
\end{aligned}
$$

Where:

$\mathrm{Y}=$ Job performance

$\mathrm{b}_{0}=$ Constant (intercept)

$\mathrm{b}_{1-9}=$ Estimates (regression coefficients)

\begin{tabular}{|c|c|c|c|c|c|}
\hline Predictors & $\begin{array}{l}\text { B (unstandardized } \\
\text { coefficients) }\end{array}$ & Std. error & $\begin{array}{l}\text { Beta (standardized } \\
\text { coefficients) }\end{array}$ & $\mathrm{t}$ & p-value \\
\hline Constant & 2.708 & 0.421 & & 6.437 & 0.000 \\
\hline Leadership development competency $\left(\mathrm{X}_{1}\right)$ & 0.023 & 0.065 & 0.025 & 0.363 & 0.717 \\
\hline \multicolumn{6}{|l|}{ Problem solving/decision making } \\
\hline Development competency on $\left(\mathrm{X}_{2}\right)$ & 0.041 & 0.055 & 0.052 & 0.739 & 0.461 \\
\hline Competency on SALM certificate program $\left(X_{3}\right)$ & -0.129 & 0.059 & -0.141 & -2.172 & 0.031 \\
\hline Social competency $\left(\mathrm{X}_{4}\right)$ & 0.188 & 0.070 & 0.208 & 2.671 & 0.008 \\
\hline Cultural competency $\left(\mathrm{X}_{5}\right)$ & 0.238 & 0.059 & 0.316 & 4.008 & 0.000 \\
\hline Program planning competency $\left(\mathrm{X}_{6}\right)$ & -0.045 & 0.078 & -0.055 & -0.580 & 0.562 \\
\hline Program implementation competency $\left(\mathrm{X}_{7}\right)$ & -0.074 & 0.063 & -0.104 & -1.185 & 0.237 \\
\hline Program evaluation competency $\left(\mathrm{X}_{8}\right)$ & 0.323 & 0.086 & 0.387 & 3.769 & 0.000 \\
\hline Extension teaching methods competency $\left(\mathrm{X}_{9}\right)$ & 0.090 & 0.058 & 0.127 & 1.535 & 0.126 \\
\hline
\end{tabular}

Table 2: Estimates of coefficients for the model
$\mathrm{X}_{1}=$ Competency on leadership development

$\mathrm{X}_{2}=$ Competency on problem solving/decision development

$\mathrm{X}_{3}=$ Competency on SALM certificate program

$\mathrm{X}_{4}=$ Competency on social skill

$\mathrm{X}_{5}=$ Competency on culture of clients

$\mathrm{X}_{6}=$ Competency on program planning

$\mathrm{X}_{7}=$ Competency on program implementation

$\mathrm{X}_{8}=$ Competency on program evaluation

$\mathrm{X}_{9}=$ Competency on teaching methods

$\mathrm{e}=$ Error

To test to what extent the research data support the MLR model of Enter regression method was used. Based on the method used, only four predictor variables were found to be significant in explaining job performance of extension workers. The four predictor variables were social skill $(\mathrm{t}=2.671, \mathrm{p}=0.008)$, Competency on culture of clients $(t=4.008, p=0.000)$, Competency on program evaluation $(\mathrm{t}=3.769, \mathrm{p}$ $=0.000)$ and competency on SALM certificate program $(\mathrm{t}=-2.172, \mathrm{p}=0.031)$.

As depicted in the coefficients Table 2, the estimates of the model coefficients for $b_{0}$ is $2.708, B_{1}$ is $0.023, \mathrm{~B}_{2}$ is $0.041, \mathrm{~B}_{3}$ is $-0.129, \mathrm{~B} 4$ is $0.188, \mathrm{~B} 5$ is $0.238, \mathrm{~B} 6$ is $-0.045, \mathrm{~B} 7$ is -0.074 , B8 is 0.323 and $\mathrm{B} 9$ is 0.090. Therefore, the estimated in Eq. 1 is as below:

$\begin{aligned} \mathrm{Y}= & 2.708+0.023\left(\mathrm{X}_{1}\right)+0.041\left(\mathrm{X}_{2}\right)-0.129\left(\mathrm{X}_{3}\right)+0.188 \\ & \left(\mathrm{X}_{4}\right)+0.238\left(\mathrm{X}_{5}\right)+-0.045\left(\mathrm{X}_{6}\right)+-0.074\left(\mathrm{X}_{7}\right)+0.323 \\ & \left(\mathrm{X}_{8}\right)+0.090\left(\mathrm{X}_{9}\right)+\mathrm{e}\end{aligned}$

To compare the strength of this coefficient to the coefficient for another variable, it can be referred to the column of Beta coefficients as known as standardized regression coefficients. As illustrated in Table 1, the largest Beta coefficient is 0.387 which is for competency on program evaluation.
Notes: $\mathrm{R}=0.737 ; \mathrm{R}^{2}=0.544 ;$ Adj. $\mathrm{R}^{2}=0.523$ 
The Beta value for competency on culture/values of clients 0.316 is the second highest, followed by Beta value for social skill competency 0.208 and The Beta value for SALM certificate program competency 0.141 is the smallest and indicating that it made the least contribution to job performance of extension workers.

As a measurement of whether the predictor is making a significant contribution to the model, it is easier to conceptualize the $t$-tests. If the t-test associated with a $\beta$ value is significant, then the predictor is making significant contribution to the model. The value of significance and the larger the value of (t), the greater contribution of that predictors. As a result in this case from the magnitude of the t-test, the four mentioned competencies are all significant predictors of extension worekrs' job performance. Competency on program evaluation is the biggest predictor followed by Competency on culture of clients, Social competency and competency on SALM program respectively according to the enter method. Thus the model is equated accordingly in Eq. 2 as:

\section{Enter method:}

$$
\begin{aligned}
& \text { Jobperformance }(Y)=2.708+0.023\left(X_{1}\right)+0.041\left(X_{2}\right) \\
& -0.129\left(X_{3}\right)+0.188\left(X_{4}\right)+0.238\left(X_{5}\right)+-0.045\left(X_{6}\right)+ \\
& -0.074\left(X_{7}\right)+0.323\left(X_{8}\right)+0.090\left(X_{9}\right)+e
\end{aligned}
$$

The findings suggest that the data dose not fully support the proposed nine-predictors multiple linear regression model. On the other words not all the competencies can explain and influence extension workers' job performance. The $\mathrm{R}^{2}$ value of 0.544 implies that the nine predictors explain about $54.4 \%$ of the variance/variation in the extension workers' job performance or $54.4 \%$ of the variability of extension workers' job performance is accounted for by the competencies in the model.

\section{DISCUSSION}

As noted earlier four competencies are significant predictors of extension workers' job performance. This finding confirms and extends the results of previous research. Results showed that program evaluation competency has the highest contribution to the job performance of the extension workers. In other words Program evaluation competency makes the strongest unique contribution to explaining job performance of the extension workers, when the variance explained by all other predictors in the model is controlled. It suggests that one standard deviation increase in competency on program evaluation lead to 0.387 standard deviation increase in job performance. This finding confirms the results of previous research conducted by Khalil et al. (2008) that this competency predicts extension workers' job performance.

Cultural competency is the second highest competency which influences job performance. This result confirms the study carried out by Tiraieyari (2009) that showed Performance of extension workers is positively related to Cultural competency $(r=0.611$, $\mathrm{p}=0.001$.

Social competency has also shown its prediction in previous studies in relation to job performance and there is sufficient evidence for the contribution. Findings of a research indicated that among all individual factors, social skill is strongest contribution in explaining extension workers' performance (Thach et al., 2008). Technical competency is the smallest and indicating that it made the least contribution to job performance of extension workers. Tiraieyari et al. (2009) has also reported that job performance of extension workers is positively related to technical aspect of their job related to the Good Agricultural Practices $(r=0.356, p$ $=0.001$ ).

The result of regression analysis in the study of analysis of the job performance of the agricultural extension experts of Iran conducted by (Rezaie et al., 2008) revealed that job ability contribute $48.6 \%$ of the variance in job performance of extension workers. Finding of another research also showed that possession of communication/social competence led to high prediction of job performance (Riggo and Tylor, 2000). Nevertheless the other five competencies (predictors) are not significant in explaining extension workers' job performance. This might be due the possibility that extension workers are relatively less involved in these aspects of study. For instance leadership development and problem solving/decision making development competency is seldom emphasized in the daily routines of extension workers. Similarly program planning decision on implement of the program done at the institutional level and this is not part of job for frontline extension workers.

\section{CONCLUSION}

In this study, four competencies influenced extension workers' job performance in the Department of Agriculture. They are cultural competency, program evaluation competency, SALM certificate competency and social competency. Despite the fact that human development competencies such as leadership development competency and problem solving/decision 
making development competency are important competencies for extension workers, in this study these competencies did not influence extension workers' job performance. This finding was contrary to expectations and didn't fully support the idea of interdependence model of extension. Hence Malaysian extension workers are not much involved in these aspects of their job and they give primary attention to technology transfer rather than human development.

According to the regression analysis program evaluation competency, cultural competency, social competency and competency on SALM program contribute to job performance. It can be concluded that the results support importance of these competencies for extension workers that ensure job performance. Hence to improve the performance of extension workers employed by department of agriculture, these competencies must be considered and upgraded.

Malaysia is a multi-ethnic, multi-cultural, multireligious and multi-lingual country. As the study has indicated that cultural competency influences extension workers' job performance, due focus should be given to this competency. It is strongly recommended for department of agriculture to undertake employment and involvement of few committed and qualified extension workers from different ethnic groups in each state of this country that can provide ongoing communication to the different clients and they can use the culture of society to the benefit of their study.

Extension workers must possess the necessary skills to not only transfer the SALM programs but also systematically evaluate program outcomes and impacts. In addition extension workers must possess the skills to use evaluation results. Designing an evaluation process that provides opportunities for improving job performance is recommended for Department of Agriculture to maximize extension workers' potential.

\section{ACKNOWLEDGEMENT}

We would like to thank the head of Institute for Social Science Studies (IPSAS), University Putra Malaysia that has provided financial support to publish these results in this journal.

\section{REFERENCES}

Armstrong, M., 2003. A Hand Book of Human Resource Management Practice. 9th Edn., Kogan Page Ltd., London, ISBN: 0749441054, pp: 979.

Belay, K. and D. Abebaw, 2004. Challenge facing agricultural extension agents: A case study from South-Western Ethiopia. Afr. Dev. Rev., 16: 139-168. DOI: $10.1111 /$ j.1467-8268.2004.00087.x
Benet, C.F., 1993. Interdependence models. J. Exten., 31: $8-10$. http://www.joe.org/joe/1993summer/a8.php

Bennett, C.F., 1989. Improving Coordination of Extension and Research. In: Foundations and Changing Practices in Extension, Blackburn, A. (Ed.). University Of Guelph, Canada, pp: 118-128.

Boyd, B.L., 2003. Competencies for leaders of volunteers during the next decade: A national Delphi study. J. Agric. Educ., 44: 47-57. http://www.leadershipeducators.org/Archives/2003 /boyd.pdf

Cooper, A.W. and D.L. Graham, 2001. Competencies needed to be successful county agents and county superiors. J. $\quad$ Exten., 39 : 1-8. http://www.joe.org/joe/2001february/rb3.php

Dhanakumars, V.G., 2001. Performance appraisal in Rubber Board Extension Delivery Systems (RBEDS). J. Agric. Exten. Manage., 2: 174-190.

Ferris, G.R., L.A. Witt and W.A. Hochwarter, 2001. Interaction of social skill and general mental ability on work outcomes. J. Applied Psychol., 86: 1075-1082. http://content.apa.org/journals/apl/86/6/1075

Gibson, J.D. and J. Hillison, 1994. Training needs of area specialized extension agents. J. Exten., 32: 1-5. http://www.joe.org/joe/1994october/a3.html

Khalil, A.H.O., M. Ismail, T. Suandi and A.D. Silong, 2008. Extension worker as a leader to farmers: influence of Extension leadership competencies and organizational commitment on extension workers' performance in Yemen. J. Int. Soc. R., 4: 368-387. http://www.sosyalarastirmalar.com/cilt1/sayi4/sayi 4pdf/khalil_and_vd.pdf

Liles, R.T. and R.D. Mustian, 2004. Core competencies: A systems approach for training and organizational development in extension. J. Agric. Educ. Exten., 10: 77-82. DOI: $10.1080 / 13892240485300121$

Linders, J.R., 2001. Competency assessment and human resource management performance of county extension chairs in Ohio. J. Agric. Educ., 42: 21-31. http://pubs.aged.tamu.edu/jae/pdf/Vol42/42-0421.pdf

Miller, R.L. and L. Cox, 2006. Technology transfer preferences of researchers and producers in sustainable agriculture. J. Exten., 44: 1-6. http://www.joe.org/joe/2006june/rb2.shtml

Olsen, L., J. Bhattacharya and A. Scharf, 2006. Cultural Competency: What it is and why it matters. was Lucile Packard Foundation for Children's Health. 
Othman, N., 2006. Malaysia's experience in training of farmers on good agricultural practice. Proceeding of the Regional Workshop on Marketing Training in the Agricultural Supply Chain, Nov. 20-24, FAO/ASMA/FAMA, Kuala Lumpur, Malaysia, pp: $1-8$.

Payne, H.J., 2005. Reconceptualizing social skills in organizations: Exploring the Relationship between communication competence, job performance and supervisory roles. J. Leadership Org. Stud., 11: 63-77. http://www.entrepreneur.com/tradejournals/article/ 128206303.html

Rezaie, A., A. Alambeigi and A. Rezvanfar, 2008. Analysis of the job performance of the agricultural extension experts of yazd province, Iran. Res. J. Agric. Biol. Sci., 4: 78-85. http://www.insipub.com/rjabs/2008/78-85.pdf

Riggo, R.E. and S.J. Taylor, 2000. Personality and communication skills as predictors of hospice nurse performance. J. Bus. Psychol., 15: 351-359. http://www.springerlink.com/content/g1j1g05k353 81306/fulltext.pdf

Rivera, W.M. and M.K. Qamar, 2003. Agricultural extension, rural development and the food security challenge. Food and Agriculture Organization of The United Nations. http://www.fao.org/DOCREP/006/Y5061E/Y5061 E00.HTM
Thach, L.N., M. Ismail, U. Jegak and K. Idris, 2008. Individual factors as predictors of extension agents' performance in Mekong delta, Vietnam. J. Hum. Resour. Adult Learn., 3: 93-102. http://www.ctu.edu.vn/departments/dra/publication /quocte052009/Le\%20Ngoc\%20Thach.pdf

Tiraieyari, N., 2009. The importance of cultural competency for agricultural extension worker in Malaysia. J. Int. Soc. Res., 2: 411-421. http://www.sosyalarastirmalar.com/cilt2/sayi8pdf/ti raieyari.pdf

Tiraieyari, N., K.H. Idris, A. Hamzah and K. Uli, 2009. Relationship between technical competency and extensionists' job performance. Res. J. Agric. Biol. Sci., 5: 533-540. http://www.insipub.com/rjabs/2009/533-540.pdf

Wayne, S.J., R.C., Liden, I.K., Graf and G.R. Ferris, 1997. The role of upward influence tactics in human resource decisions. J. Personn. Psychol., 50: 979-1006. DOI: $10.1111 /$ j.17446570.1997.tb01491.x 